\title{
SIMULATION OF SOLAR INTENSITY IN PERFORMANCE OF FLAT PLATE COLLECTOR
}

\author{
A.Ponshanmugakumar ${ }^{1}$, A. Aldrich Vincent ${ }^{2}$
}

\begin{abstract}
Solar collectors behave differently at different radiations and temperatures. The system consists of solar thermal collectors, a storage and circulation pump of water to carry the heat to its applications. The results of the simulations show that, the efficiency of flat plate collectors can be used for domestic purposes in Tamil Nadu at different geographic locations by adjusting the characteristics of system components to obtain results. It also helps in determining the location which generates optimum solar energy. This study intends to focus on the performance of flat plate collectors in a simulation environment using TRNSYS and solar radiation data collected for 7 stations in Tamil Nadu
\end{abstract}

Keywords: Flat Plate Collector (FPC), TRNSYS, Solar Intensity

\section{INTRODUCTION}

In the recent years the energy production is the major problem. Their cost and the pollution while consuming fossil fuels. The depreciation of fuels is also a major frightening issue. But fossil fuels are the most commonly used and depend fuels. So in order to reduce the problem the rulers has encouraging for the alternative energy sources. It is most commonly called as renewable energy sources and it has no pollution, regenerative type and also safe generation of power. Among all the alternative energy sources solar energy has a high impact on energy production

\subsection{Solar Radiation}

The spectrum of electromagnetic wave radiation produced by sun is solar radiation. The earth's atmosphere deflects or filters the majority of the sun's damaging radiation. About part of the radiation is in the observable short-wave division of the electromagnetic range. The other half is mostly in the infrared part, with some in the ultraviolet.

\subsection{Characteristics of Solar Radiation}

The part of solar radiation is intercepted by the earth's outer atmosphere. The statistical relation formulated between the daily duration of sunshine $\mathrm{N}$ and the daily total global solar radiation $\mathrm{G}$ is of the form,

$$
\left(\frac{G}{G_{o}}\right)=a+(1-a)\left(\frac{n}{N}\right)(1.1)
$$

Where, Go is the daily global solar radiation with cloud free atmosphere, 'a' is mean proportion of radiation on an entirely overcast day, and N; maximum period of sunshine. Due to the difficulties in the defined estimation of Go in the above equation, Go was replaced by the celestial radiation (ECR), it is given by,

$$
\left(\frac{G}{E T R}\right)=a+b\left(\frac{n}{N}\right)(1.2)
$$

\subsection{Flat Plate Collectors}

The flat plate collectors ar5e most commonly used in the domestic hot water system on the roof tops. They consist of a black coated absorber, a transparent acrylic cover that reduces heat losses, a heat transfer fluid to extract heat from the absorber, and a heat insulating packing. In water heat panels, fluid is usually circulated through tubes to transfer heat from the absorber to an insulated storage tank. This may be achieved directly or through a heat exchanger.

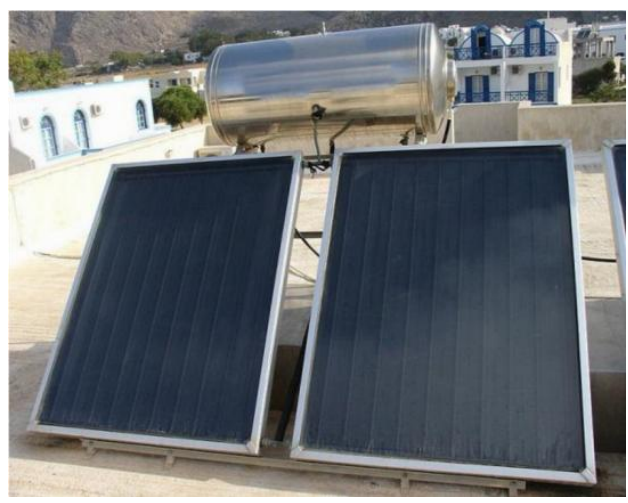

Fig 1 Flat plate collectors

Hilmer et al. 1999 presented a method to calculate numerically the solar collector with varying parameters [1] Zuefa and Magiera 2001 published an experimental study in the more uniform for the flow distribution, the higher the collector efficiency. But uniform flow distributions are not possible in solar collectors [2]. Fan et al. 2007 investigated both experimentally and theoretically the finned tube flat plate collector. They analyzed numerically by CFD and got results which oriented with experiment results [3].

Augustus and Kumar 2006 developed mathematical model for an unglazed perforated flat plate collector. They developed an empirical relation for various components. They proved the improved results of absorptivity, heat transfer and air flow rate[4]. Molero et al. 2009 presented a 
3-D numerical model for flat-plate solar collector considering the transient conditions like flow characteristics. But this un-uniform flow does not make huge effect in collector efficiency. When the dimensions of the tube increases with the flow increases with due change in collector efficiency [5].

Anderson et al 2009[6] examined the performance by changing the colours of solar collector. Based on the transmittance-absorptance result of various colored collectors the hypothetical performances of these collectors were calculated using the Hottel-Whillier-Bliss 1-D steadystate model given by Duffie and Beckmann 2006[7]. By these experiments they concluded that the colour of the collector plays a major role in thermal efficiencies of the collectors.

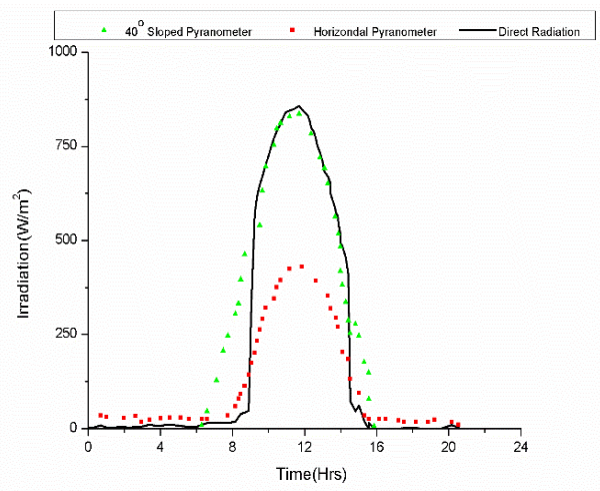

Fig 2 Irradiation data of Flat plate collector

\subsection{Domestic Hot Water System (DHWS)}

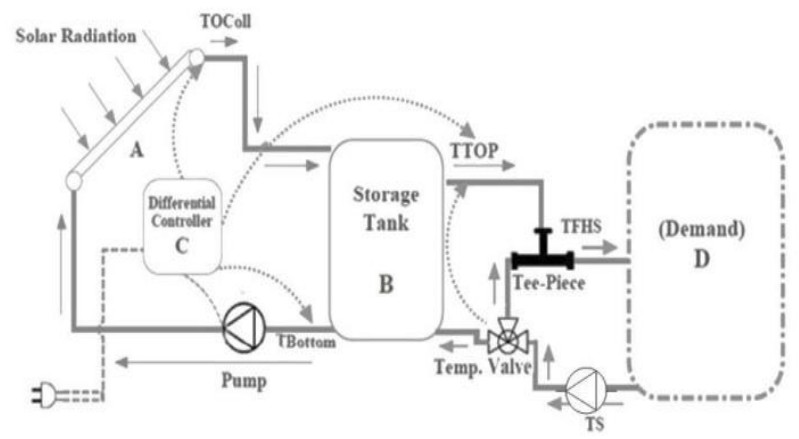

Fig 3 Schematic diagram of solar water heating system

The various day of the year weather data's are absorbed by the solar collector (A). Flat Plate Collector (FPC) were connected in array in parallel arrangements. To improve the hot water system performance and to study the stratification of the storage tank a hot water storage tank (B) was used here. As a outcome, a temperature variation between the top and the bottom parts of the tank arises the density variation between top and bottom. The high density fluid come to the bottom side and the low density fluid to the top of the tank. An on/off differential controller (C) is use to control the temperature variation between $\mathrm{T}_{\mathrm{OColl}}$ and $\mathrm{T}_{\mathrm{Bottom}}$. Controlling the temperature can have a significant effect on the final result. In this case, the $\mathrm{T}_{\text {OColl }}$ is adjusted as the Upper input temperature $\mathrm{T}_{\mathrm{h}}, \mathrm{T}_{\text {Bottom }}$ is adjusted as Lower input temperature $\mathrm{T}_{1}$ and $\mathrm{T}_{\mathrm{TOP}}$ is adjusted as Monitoring temperature $\mathrm{T}_{\mathrm{in}}$. The temperature data's from hot and cold water side sends the appropriate signal to the pump according to the dead bands. There is a high limit cut out temperature that can be defined as desired.

\section{SYSTEM AND MATHEMATICAL MODEL}

\subsection{Solar Collectors}

The flat plate collector (quadratic efficiency) Type $1 \mathrm{~b}$ is selected from TRNSYS component libraries. This component models the thermal performance of a flat- plate solar collector. The number of modules in series and the characteristics of each module determine the thermal performance of the collector array. Equation 1 gives the solar collector thermal efficiency.

$$
\eta_{\text {col }}=m \cdot c_{p}\left(T_{o-c o l}-T_{i-c o l}\right) / A_{c o l} I_{t}(i)
$$

TRNSYS models of solar collectors have different types of functions named parameters, inputs and outputs. A parameter value function is specifically related to the manufacturer (Thermo Dynamics Ltd.). These values need to be input according to manufacturer specifications. An input value function has a value that depends upon the test conditions, such as collector slope, orientation, etc. Some inputs and all outputs have a 'linked' value, which means that this function has values, which are linked to other components and will be determined by the real time flow.

\subsection{Theoretical Flat-Plate Collector}

The energy compilation of each component in an array of $\mathrm{N}_{\mathrm{s}}$ modules in series is modeled according to the HottelWhillier equation such that ( $\mathrm{j}$ is the module number):

$$
\mathrm{Q}_{\mathrm{u}}=\frac{\mathrm{A}}{\mathrm{N}_{\mathrm{s}}} \sum_{\mathrm{j}=1}^{\mathrm{N}_{\mathrm{s}}} \mathrm{F}_{\mathrm{Rj}}\left(\mathrm{I}_{\mathrm{T}}\left(\tau \alpha_{\mathrm{a}}\right)-\mathrm{U}_{\mathrm{Lj}}\left(\mathrm{T}_{\mathrm{ij}}-\mathrm{T}_{\mathrm{a}}\right)\right)
$$

Where $F_{R, j}$ can be explained as follows:

$$
F_{R j}=\frac{N_{s} m_{c} C_{p c}}{A U_{L j}}\left(1-\exp \left(-\frac{F U_{L j} A}{N_{s} m_{c} C_{p c}}\right)\right)
$$

The following expression, developed by Klein, is used to approximate $\mathrm{U}_{\mathrm{L}, \mathrm{j}}$ (in $\mathrm{KJ} / \mathrm{h}-\mathrm{m} 2-\mathrm{K}$ ). Equation (iii) is described as:

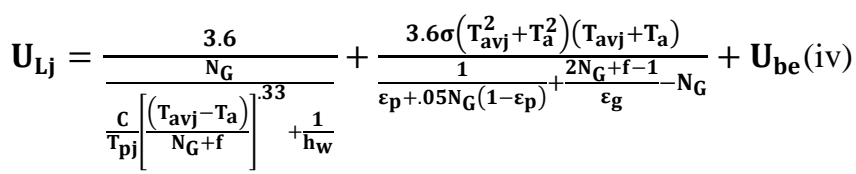

And

$$
\begin{aligned}
\mathrm{Hw} & =5.7+3.8 \mathrm{~W}(\mathrm{~W} / \mathrm{m} 2-\mathrm{K}) \\
\mathrm{f} & =(1-0.04 \mathrm{hw}+0.0005 \mathrm{hw} 2)(1+0.091 \mathrm{NG})(\mathrm{vi})
\end{aligned}
$$


The overall transmittance - absorptance product is determined as:

$$
\left(\tau \alpha_{a}\right)=\frac{I_{b t}\left(\tau \alpha_{a}\right)_{b}+I_{d}\left(\frac{1+\cos \beta}{2}\right)\left(\tau \alpha_{a}\right)_{s}+\rho I\left(\frac{1-\cos \beta}{2}\right)\left(\tau \alpha_{a}\right)_{g}}{I_{T}}
$$

Where $I_{b t}$ is beam radiation incident on the solar collector, $I_{d}$ is diffuse horizontal radiation and IT is global radiation incident on the solar collector (Tilted surface). The outlet temperature of one module is used as the inlet to the next and is given as:

$$
\mathbf{T}_{\mathbf{o}, \mathbf{j}}=\frac{\mathrm{AF}_{\mathrm{Rj}}\left(\mathbf{I}_{\mathbf{T}}\left(\tau \boldsymbol{\alpha}_{\mathbf{a}}\right)-\mathrm{U}_{\mathrm{L}, \mathrm{j}}\left(\mathrm{T}_{\mathrm{i}, \mathrm{j}}-\mathbf{T}_{\mathbf{a}}\right)\right)}{\mathbf{N}_{\mathbf{s}} \mathbf{m}_{\mathbf{c}} \mathbf{C}_{\mathbf{p c}}}+\mathbf{T}_{\mathbf{i}}
$$

If the collector flow is zero, the collector stagnation temperature is:

$$
T_{p}=\frac{I_{T}\left(\tau \alpha_{a}\right)}{U_{L}}+T_{a}
$$

\subsection{Solar Radiation on a Tilted Surface}

The amount of solar radiation incident on a tilted component plane is the element of the incident solar radiation which is upright to the module surface. The following figure shows how to calculate the radiation incident on a tilted plane $\left(\mathrm{S}_{\text {module }}\right)$ given either the solar radiation measured on horizontal surface $\left(S_{\text {horiz) }}\right.$ or the solar radiation calculated vertical to the sun $\left(S_{\text {incident }}\right)$.

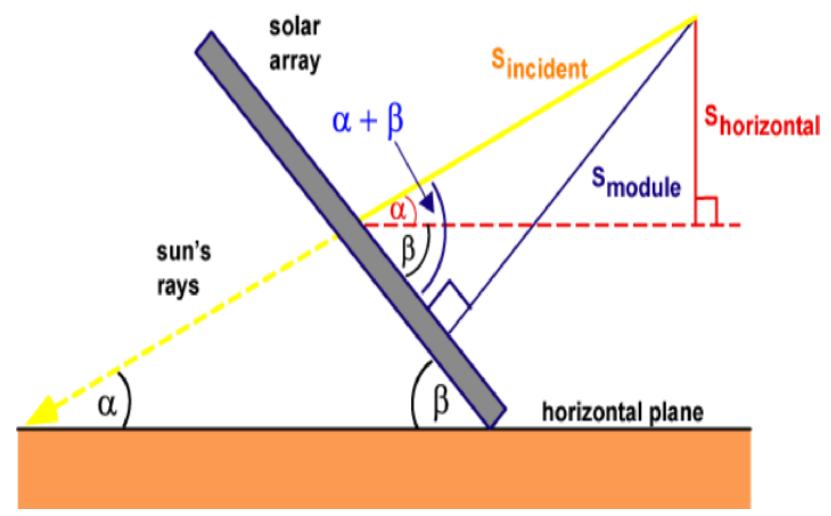

Fig 4 Tilted flat plate collector

The equations relating $\mathrm{S}_{\text {module }}, \mathrm{S}_{\text {horiz }}$ and $\mathrm{S}_{\text {incident }}$ are:

$$
\begin{gathered}
S_{\text {horizontal }}=S_{\text {incident }} \sin \alpha(4.10) \\
S_{\text {module }}=S_{\text {incident }} \sin (\alpha+\beta)(\mathrm{x})
\end{gathered}
$$

Where,

$\alpha$ is the elevation angle $\beta$ is the tilt angle of the module measured from the horizontal.

The elevation angle has been previously given as:

$$
\alpha=90-\phi+\delta_{(\mathrm{xi})}
$$

$\varphi$ is the latitude $\delta$ is the declination angle previously given as:

$$
\delta=23.45^{\circ} \sin \left[\frac{360}{365}(284+d)\right]
$$

Where, $\mathrm{d}$ is the day of the year. Note that from simple math $(284+d)$ is equivalent to (d-81) which was used before. Two equations are used interchangeably in literature.

From these equations a relationship between $S_{\text {module }}$ and $\mathrm{S}_{\text {horiz }}$ can be determined as:

$$
S_{\text {module }}=\frac{S_{\text {horizontal }} \sin (\alpha+\beta)}{\sin \alpha}
$$

The following active equations show the calculation of the incident and horizontal solar radiation and that on the module. Enter only one of $\mathrm{S}_{\text {module }}, \mathrm{S}_{\text {horiz }}$ and $\mathrm{S}_{\text {incident }}$ and the program will calculate the others.

To calculate the incident angle of one station - Trichy :

Latitude $\phi=10$, Longitude $\lambda=78$,

GMT offset $=5.00 \mathrm{hrs}$,

Declination angle $\delta=-23.01$

To find incident angle $\alpha=$ ?

$$
\alpha=90-\phi+\delta=90-10-23.01=56.99
$$

herefore, the angle of incident $\alpha=56.99$ Incident radiation $=$ $500 * 12 \mathrm{Wh} / \mathrm{m}^{2}$ Total horizontal radiation $=541 * 12 \mathrm{Wh} / \mathrm{m}^{2}$ Horizontal diffuse radiation $=170 * 12 \mathrm{Wh} / \mathrm{m}^{2}$

Applying incident angle and 3 radiations as input for TRNSYS simulation

\section{MODELING OF FLAT PALTE COLLECTOR USING SOLAR ENERGY}

For creating the project in TRNSYS simulation studio the desired components should be selected from the list available in the components library. The modeling schemes of the system are designed according to Figure as shown in Figures 5. In this figure components are connected to each other in the proper way which yields the initial aim described in section 2. In Figure 5, flat plate collectors are used to utilize solar energy. The components have been chosen from standard and TESS libraries from TRNSYS software which are listed in Table 1. Each component has its own properties and some of them have specific mathematical description.

Where, 


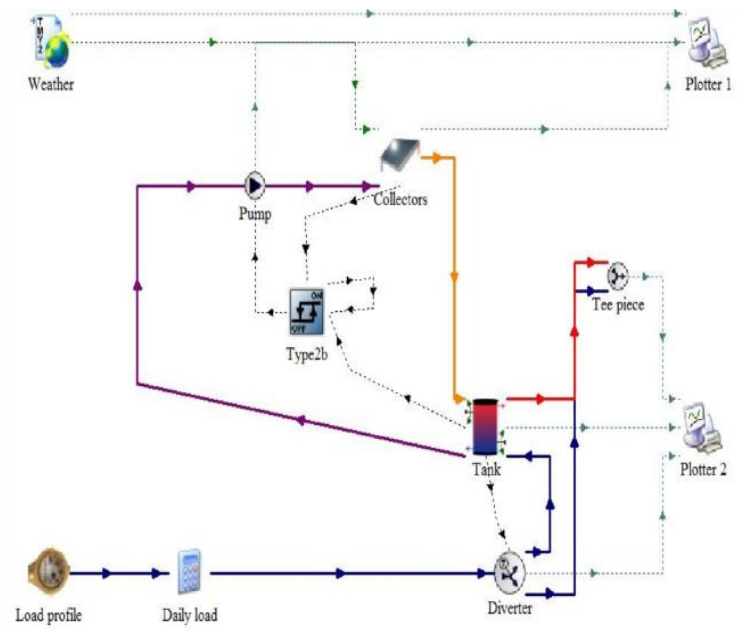

Fig 5 Modeling scheme of the system using Flat Plate Collector

Table 1 Components used in Simulation Studio

\begin{tabular}{|l|l|}
\hline $\begin{array}{l}\text { Component } \\
\text { (TYPE) }\end{array}$ & Description \\
\hline Type109-TMY2 & $\begin{array}{l}\text { Weather Data Reading and } \\
\text { Processing }\end{array}$ \\
\hline Type 73 & Theoretical Flat-Plate Collector \\
\hline Type 3d & $\begin{array}{l}\text { Single Speed - No Power coefficients } \\
\text { Pump }\end{array}$ \\
\hline Type 2b & Differential Controller \\
\hline Type 4c & Stratified Storage Tank \\
\hline Type 11h & Tee-Piece \\
\hline Type 11f & Flow Diverter \\
\hline Type 65a & Online Plotter \\
\hline
\end{tabular}

In this system, TMY2 is reading the weather information regularly, and checking the solar radiation data to find tilted surface radiation and angle of incidence for an arbitrary number of surfaces. Tamil Nadu climate conditions are used for simulation. The weather data are given on hourly basis. Type 73 and 74 are the models for the thermal performance of a theoretical flat plate collector which is shown in Figures 5 .

The parameters of FPC are adjusted in the system are shown in Tables 2.

Table 2 Flat-Plate Collector parameters

\begin{tabular}{|l|l|}
\hline $\begin{array}{l}\text { Number in } \\
\text { series }\end{array}$ & 1 \\
\hline Collector area & $5 \mathrm{~m}^{2}$ \\
\hline $\begin{array}{l}\text { Fluid specific } \\
\text { heat }\end{array}$ & $4.19 \mathrm{~kJ} / \mathrm{kg} . \mathrm{K}$ \\
\hline $\begin{array}{l}\text { Intercept } \\
\text { efficiency }\end{array}$ & 0.80 \\
\hline Collector slope & $45^{\circ}$ \\
\hline Inlet flowrate & $100 \mathrm{~kg} / \mathrm{hr}$ \\
\hline
\end{tabular}

Type $2 \mathrm{~b}$ is the differential controller component which is monitoring TTOP by comparing the comparing ToColl and
TBottom. The input properties of this controller are shown in Table 3. When TOColl is greater than TBottom, the controller actuates the pump. If the temperature TTOP reaches $100^{\circ} \mathrm{C}$, the pump is stopped.

Table 3 Differential Controller input parameters

\begin{tabular}{|l|l|}
\hline $\begin{array}{l}\text { High limit } \\
\text { cut-out }\end{array}$ & $100^{\circ} \mathrm{C}$ \\
\hline $\begin{array}{l}\text { Upper input } \\
\text { temperature } \\
\mathrm{T}_{\mathrm{h}}\end{array}$ & $\mathrm{T}_{\mathrm{O}}$ Coll \\
\hline $\begin{array}{l}\text { Lower } \\
\text { input } \\
\text { temperature } \\
\mathrm{T}_{1}\end{array}$ & \\
\hline $\begin{array}{l}\text { Monitoring } \\
\text { temperature }\end{array}$ & $\mathrm{T}_{\text {Bottom }}$ \\
$\mathrm{T}_{\text {in }}$ & $\mathrm{T}_{\mathrm{TOP}}$ \\
\hline
\end{tabular}

Type $3 \mathrm{~d}$ is a single speed pump which is either 'on' or 'off' according to the signal received from Type $2 \mathrm{~b}$. When the pump is 'on' the flow rate of water will be $125 \mathrm{~kg} / \mathrm{hr}$.

Type $4 \mathrm{c}$ is the stratified tank which fluid is stored in it during the night time and it's also connected to the type $2 b$ for specifying the $\mathrm{Tl}$ and Tin.

Type $11 \mathrm{~h}$ is the Tee-piece in which two inlet liquid streams are mixed together into a single liquid outlet stream. The outlet fluid from the Tee-piece needs to be transferred to the demand (D)(Fig 3). Type $11 \mathrm{f}$ is the flow diverter, which is a single inlet liquid stream.

During the simulation, the results need to be shown in graphs and tables. Type $65 \mathrm{a}$ is the online plotter that is used to display selected system variables while the simulation is progressing. This component is highly recommended and widely used since it provides valuable variable information and allows users to immediately see if the system is not performing as desired.

\section{RESULTS AND DISCUSSION}

The characteristics of system components are adjusted to obtain the most optimum results. The aim is to model flat plate collector for domestic purposes under Tamil Nadu weather conditions and comparing the efficiency of flat plate collector at different geographic locations. The simulations have been accomplished from March $11^{\text {th }}-15^{\text {th }}$ 2014.

The hourly variation of inlet and outlet water flow temperature - flat plate collector $-11^{\text {th }}$ to $15^{\text {th }}$ March for 7 locations in Tamil Nadu the graphs are shown below. 


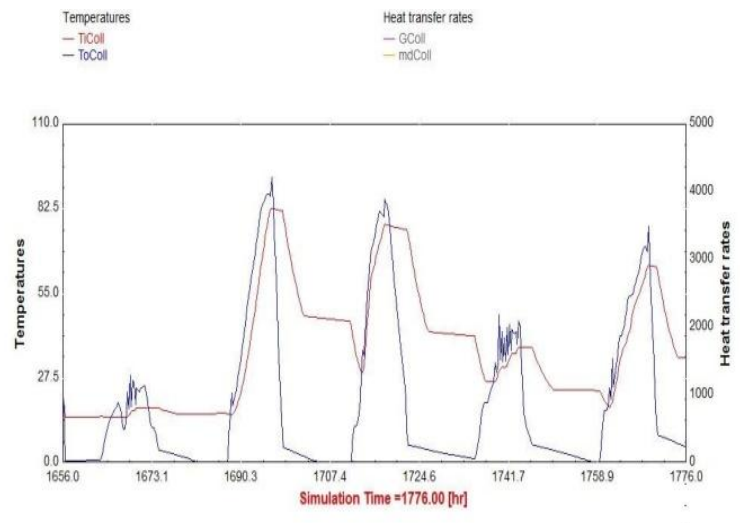

Fig 6 SRRA station at Trichy

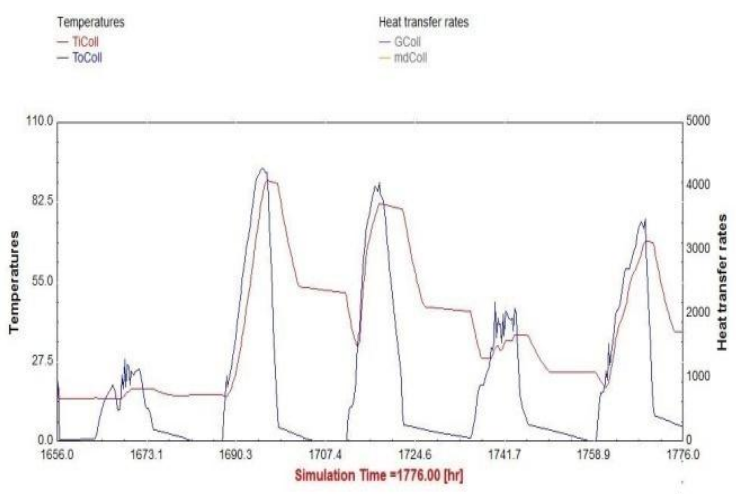

Fig 7 SRRA station at Vellore

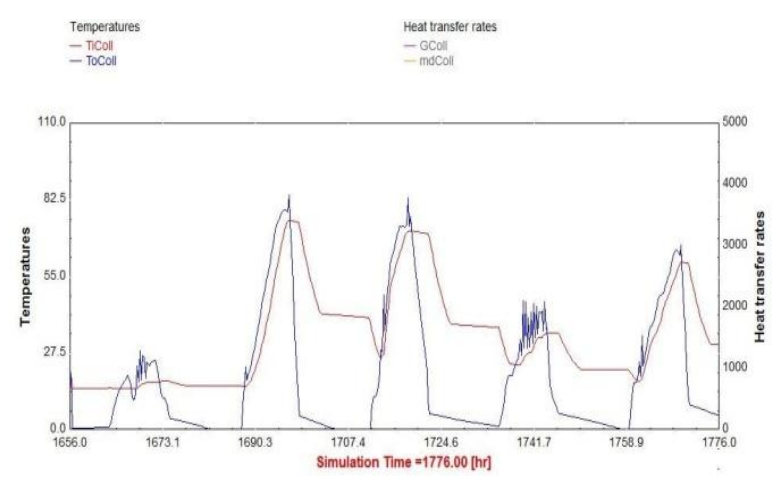

Fig 8 SRRA station at Ramanathapuram

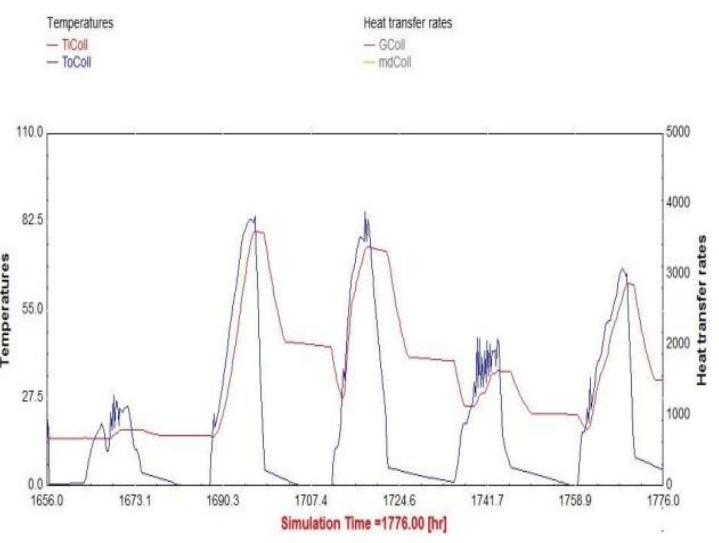

Fig 9 SRRA station at Chennai

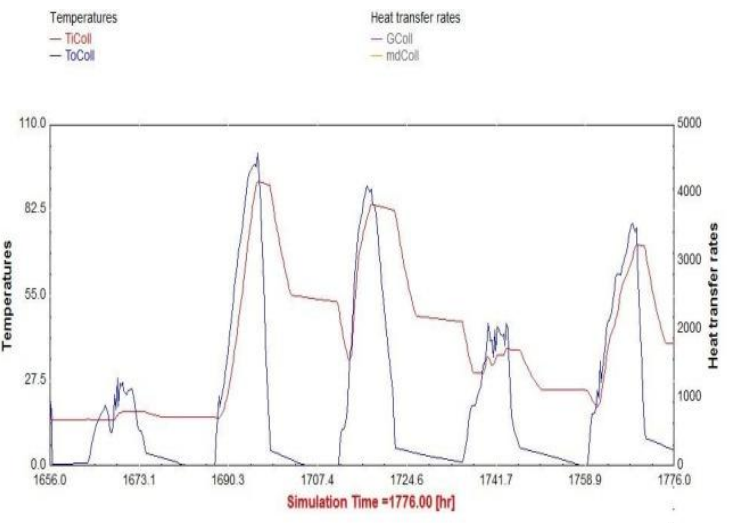

Fig 10 SRRA station at Erode

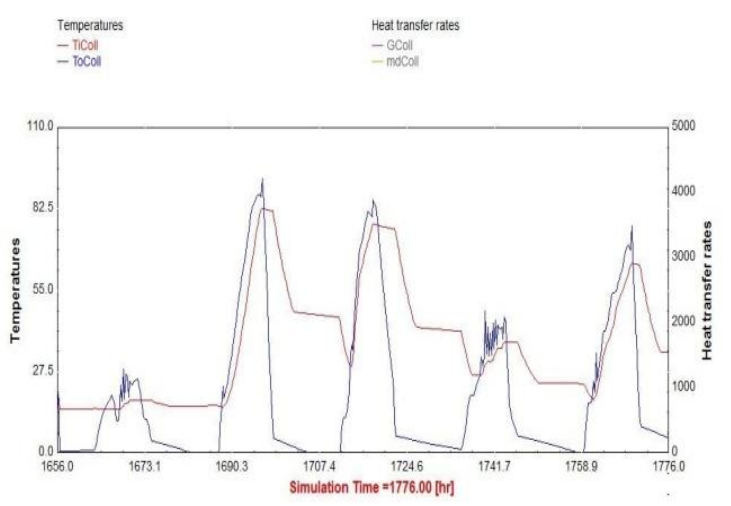

Fig 11 SRRA station at Karaikudi

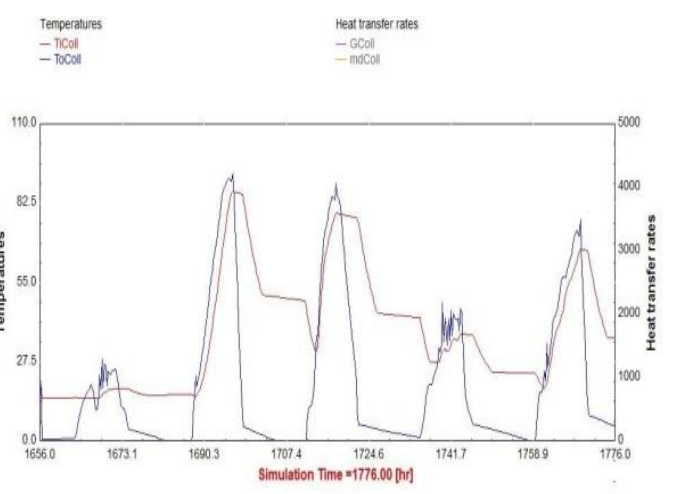

Fig 12 SRRA station at Kayathar

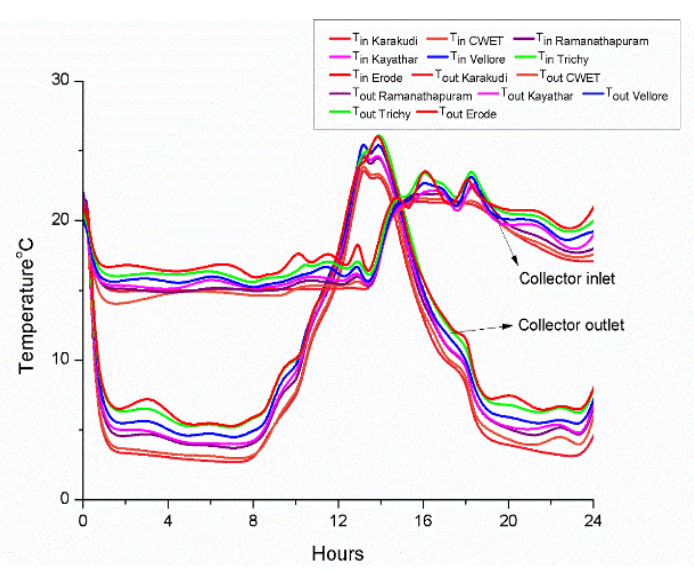

Fig 13 Comparison of all stations 


\section{CONCLUSIONS}

Solar energy is important to meet the increasing demand of energy required for daily domestic needs. Therefore, an extensive research has been done to model the flat plate collector and predict the performance of different locations in Tamil Nadu. The aim of this study is to simulate the maximum use of solar radiation in 7 geographic locations in Tamil Nadu using TRNSYS software. The hourly investigations are performed for five days from $11^{\text {th }}-15^{\text {th }}$ March and radiations are taken for the various locations. The results were simulated and the graphs were compared. It was observed that Erode had the maximum output performance using flat plate collector which can be used to replace the energy consumption of non-renewable resources.

\section{ACKNOWLEDGMENTS}

This work was supported by Center for Wind Energy Technology (CWET), Chennai for data Collection.

\section{REFERENCES}

[1]. f. Hilmer, k.Vajen,a.Ratka, h.Ackermann, w.Fuhs, o.Melsheimer, Numerical solution and validation of a dynamic model of solar collectors working with varying fluid flow rate, solarenergy,volume65, issue 5, 1999, 305-321. [2]. Zueva G. and Magiera J., 2001, Mathematical model of heat transfer in solar collector and its experimental validation, Theoretical Foundations of Chemical Engineering, 35, 6, 604-608.

[3]. Fan J., Shah L., and Furbo S., 2007, Flow distribution in a solar collector panel with horizontally inclined absorber strips, Solar Energy, 81, 1501-1511.

[4]. Augustus M. and Kumar S., 2007, Mathematical modeling and thermal performance analysis of unglazed transpired solar collectors, Solar Energy, 81, 62-75.

[5]. Molero Villar N., Cejudo Lopez J., and Dominguez Munoz F., 2009, Numerical 3-D heat flux simulations on flat plate solar collectors, 83, 1086-1092.

[6]. Anderson T., Duke M., and Carson J., 2010, The effect of color on the thermal performance of building integrated solar collectors, Solar Energy Materials \& solar cells, 94, 350-354.

[7]. Duffie J. and Beckmann W., 1991, Solar engineering of thermal processes, 2nd edition (Wiley Interscience, New York). 